\title{
Overexpression of MUC13, a Poor Prognostic Predictor, Promotes Cell Growth by Activating Wnt Signaling in Hepatocellular Carcinoma
}

Yongdong Dai, ${ }^{\dagger}$ Lulu Liu, ${ }^{*}$ Tingting Zeng, ${ }^{*}$ Jian-Zhong Liang, ${ }^{*}$ Ye Song, ${ }^{*}$ Kai Chen, ${ }^{*}$ Yan Li, ${ }^{\S}$ Leilei Chen, ${ }^{\circledR}$ Ying-Hui Zhu, ${ }^{*}$ Jiangchao Li, ${ }^{*}$ Yan $\mathrm{Li},{ }^{*}$ Dan Xie, ${ }^{*}$ Yun-Fei Yuan, ${ }^{*}$ and Xin-Yuan Guan* ${ }^{*}$

Accepted for publication

October 19, 2017.

Address correspondence to Xin-Yuan Guan, Ph.D., Room 728, The Second Bldg., 651 E. Dongfeng Rd., Guangzhou 510060, China. E-mail: xyguan@hku.hk.

\begin{abstract}
Recently RNA sequencing revealed high mucin 13 (MUC13) expression in hepatocellular carcinoma (HCC) tissues. To understand the clinicopathologic significance of MUC13 in HCC, quantitative PCR and immunohistochemistry were used to detect its expression in paired tumor tissues and nontumor tissues. The oncoprotein role of MUC13 was determined by in vitro and in vivo assays. Overexpression of MUC13 was detected in 74 of 168 primary HCC cases $(44 \%)$ and was significantly associated with tumor size $(P=0.027)$, stage $(P=0.006)$, encapsulation $(P=0.044)$, venous invasion $(P=0.024)$, and poor outcome $(P=0.004)$. Functional studies demonstrated MUC13 had strong oncogenic activity by promoting cell growth, colony formation, cell migration, and tumor formation in nude mice. The pro-oncogenic effect of MUC13 were effectively inhibited by RNA interference. MUC13 promoted cellular $\mathrm{G}_{1} / \mathrm{S}$ phase transition by activating Wnt signaling. Mechanistically, MUC13 bound to $\beta$-catenin and increased its phosphorylation at Ser552 and Ser675 sites, which subsequently promoted nuclear translocation of $\beta$-catenin and up-regulation of its downstream target genes Axin2, c-Myc, and CyclinD1. Knockdown of AKT with shRNA in MUC13-overexpressing cells nullified the elevated phosphorylation of $\beta$-catenin by MUC13. In clinical HCC samples, nuclear translocation of $\beta$ catenin was significantly associated with MUC13 overexpression $(P=0.001)$. Overexpression of MUC13 plays a critical role in the development and progression of HCC by activating Wnt signaling. (Am J Pathol 2018, 188: 378-391; https://doi.org/10.1016/j.ajpath.2017.10.016)
\end{abstract}

Hepatocellular carcinoma (HCC) ranks as the fifth most common malignancy and the third leading cause of cancerrelated death worldwide. ${ }^{1}$ Similar to other solid tumors, the pathogenesis of HCC is believed to be a long process that involves the accumulation of multiple genetic and epigenetic aberrations. ${ }^{2}$ Despite intensive study, the detailed molecular mechanisms of HCC pathogenesis remain unclear. Recently, we used integrative RNA sequencing to compare RNA expression profiles between three pairs of HCC clinical samples and detected increased expression of $M U C 13$ in all tumor tissues compared with their matched nontumor counterparts. ${ }^{3,4}$

Mucin 13 (MUC13) is a glycoprotein of the mucin family that plays an important role in the protection, lubrication, and hydration of the apical surfaces of epithelial cells in gastrointestinal and respiratory tracts. ${ }^{5}$ As transmembrane mucin, MUC13 has a short cytoplasmic tail that includes eight serine

Supported by National Natural Science Foundation of China grants 81402131 (Y.D.), 81602128 (L.L.), 81472250 (X.-Y.G.), and 81672357 [Y.L. (from Sun Yat-sen University Cancer Center)]; National Basic Research Program of China grant 2012CB967001 (X.-Y.G.); China National Key SciTech Special Project of Infectious Diseases grant 2013ZX10002-011-005 (X.-Y.G.); Hong Kong Research Grant Council General Research Funds grants HKU/7668/11M and 767313 (X.-Y.G.); Hong Kong RGC Collaborative Research grants C7038-14G and C7027-14G (X.-Y.G.); and Hong Kong Theme-based Research Scheme fund grant T12-403/11 (X.-Y.G.).

Y.D., L.L., and T.Z. contributed equally to this work.

Disclosures: None declared. 
and two tyrosine residues with potential for phosphorylation. ${ }^{6}$ Aberrant expression of MUC13 has been detected in gastric, ${ }^{7-9}$ colorectal, ${ }^{10,11}$ pancreatic, ${ }^{12,13}$ ovarian, ${ }^{14}$ esophageal, $^{15}$ and renal ${ }^{16}$ cancers. In ovarian cancer, MUC13 induces changes in cellular structure and promotes cell motility and proliferation through modulation of c-Jun N-terminal kinase, serine/threonine-protein kinase 1, and p38 mitogen-activated protein kinase signaling pathways. ${ }^{14}$ In pancreatic cells, MUC13 promotes cell growth and motility by direct interaction with the receptor tyrosine kinase human epidermal growth factor receptor 2, subsequently up-regulating serine/threonine-protein kinase 1/extracellular signal-regulated kinase/AKT signaling and down-regulating p53. ${ }^{12,17,18}$ Recently, miR-145, miR-132-3p, and Janus kinase 2/STAT5 signaling were found to regulate MUC13 expression by transcriptional activation and posttranscriptional inhibition, respectively. ${ }^{17,19,20}$ However, the role of MUC13 in HCC development remains unknown. Here, we investigated the expression pattern and clinical significance of MUC13 in HCC and characterized its oncogenic effects and the underlying mechanisms.

\section{Materials and Methods}

\section{Clinical Samples and Cell Lines}

A total of 168 pairs of HCC samples, including tumor tissues and matched nontumor tissues, were collected from Sun YatSen University Cancer Center (Guangzhou, China). Patient consent and approval from the Committees for Ethical Review of Research at Sun Yat-Sen University were obtained before sample collection. The clinicopathologic characteristics for the study series are summarized in Table 1 . The mean follow-up of censored observations was 81.1 months for overall survival (OS) and 60.0 for disease-free survival (DFS). Two immortalized normal liver cell lines, MIHA and LO2, and seven HCC cell lines, QSG7701, QGY7703, BEL7402, SMMC7721, HepG2, Huh7, and PLC8024, used in the present study have been previously described. ${ }^{3,21,22}$

\section{Plasmids and Cell Transfection}

Lentiviral plasmids that contain full-length $M U C 13$ or shRNA against $M U C 13$ were purchased from Gene Copoeia Inc. (Rockville, MD). Full-length MUC13 was stably transfected into LO2 and SMMC7721 cells with the use of Lipofectamine 2000 (Invitrogen, Carlsbad, CA) according to the manufacturer's instructions. Empty vector plasmids were used as controls. shRNA plasmid was stably transfected into Huh7 and PLC8024 cells with the use of Lipofectamine 2000 (Invitrogen). A scrambled shRNA was used as control.

\section{Silencing AKT with shRNA}

AKTshRNA (shAKT) and negative control shRNA lentiviruses were purchased from Genechem (Shanghai, China).
MUC13-overexpressing cells and control cells were infected with shAKT or negative control shRNA lentiviruses at 50 multiplicity of infection. Interference efficiency was confirmed when AKT protein level in shAKT cells showed $>70 \%$ reduction compared with that of negative control shRNA cells.

\section{In Vitro Functional Assays}

For the cell growth assay, $1 \times 10^{3}$ cells per well were seeded in a 96-well plate, and cell growth rate was determined with a CCK-8 kit (Tojindo, Shanghai, China) according to the manufacturer's instructions. For the foci formation assay, $1 \times 10^{3}$ cells per well were seeded in a 6-well plate. After culture for 14 days, cells were stained by crystal violet and clones were counted. For the invasion assay, $5 \times 10^{4}$ cells were suspended in serum-free medium and loaded into the upper compartment of an invasion chamber coated with Matrigel (Becton Dickinson Labware, Franklin Lakes, NJ). The lower compartment was filled with complete medium as a chemoattractant. After 24 hours invasive cells were fixed, stained, and counted. Triplicate independent experiments were performed for all assays.

\section{In Vivo Tumorigenicity Assay}

MUC13 oncogenic function was determined in vivo with the use of a xenograft mouse model. The indicated number of MUC13-expressing cells in complete medium was injected subcutaneously into the flank of nude mice $\left(4 \times 10^{6}\right.$ cells for LO2, $2 \times 10^{6}$ cells for SMMC7721, $1 \times 10^{6}$ cells for Huh7, $2 \times 10^{6}$ cells for PLC8024). Mice were sacrificed after 4 weeks, and the tumors were dissected and measured. All animal experiments were conducted with consent of the Committee of the Use of Live Animals in Teaching and Research at Sun Yat-Sen University.

\section{Cell Cycle Analysis}

Trypsinized cells were fixed in $70 \%$ ethanol overnight and stained with propidium iodide for 30 minutes. DNA content was analyzed by flow cytometry (Cytomics FC 500; Beckman Coulter, Brea, CA). Multicycle AV software for Windows (Phoenix Flow Systems, San Diego, CA) was used to analyze the results.

\section{RNA Extraction and $q P C R$}

TRIzol reagent (Invitrogen) was used to extract total RNA from cultured cells or frozen tissues. Reverse transcription was performed with a reverse transcription PCR kit (Roche, Basel, Switzerland) with $2 \mu \mathrm{g}$ of total RNA. Real-time quantitative PCR (qPCR) was performed with the SYBR Green PCR Kit (Roche) on an ABI PRISM 7900 sequence detection system. The relative levels of expression were quantified and analyzed with SDS software version 2.3 (Applied Biosystems, Foster City, CA). The relative 
Table 1 Clinicopathologic Correlation of MUC13 mRNA Expression in HCC

\begin{tabular}{|c|c|c|c|c|c|}
\hline \multirow[b]{2}{*}{ Feature } & \multirow[b]{2}{*}{ All, $n^{*}$} & \multirow[b]{2}{*}{$r^{\dagger}$} & \multicolumn{2}{|c|}{ MUC13 expression level } & \multirow[b]{2}{*}{$P$} \\
\hline & & & Normal & Up-regulated & \\
\hline \multicolumn{6}{|l|}{ Sex } \\
\hline Female & 25 & & 15 & 10 & \\
\hline Male & 143 & 0.034 & 79 & 64 & 0.659 \\
\hline \multicolumn{6}{|l|}{ Age } \\
\hline$\leq 60$ years & 137 & & 79 & 58 & \\
\hline$>60$ years & 31 & 0.072 & 15 & 16 & 0.347 \\
\hline \multicolumn{6}{|c|}{ Hepatitis B surface Ag } \\
\hline Negative & 27 & & 13 & 14 & \\
\hline Positive & 137 & -0.082 & 81 & 56 & 0.292 \\
\hline \multicolumn{6}{|l|}{ Serum AFP } \\
\hline $\log 10, \mathrm{ng} / \mathrm{mL}$ & $2.44 \pm 1.43$ & & $2.57 \pm 1.47$ & $2.25 \pm 1.39$ & 0.159 \\
\hline \multicolumn{6}{|l|}{ Cirrhosis } \\
\hline Negative & 39 & & 19 & 20 & \\
\hline Positive & 123 & -0.085 & 72 & 51 & 0.282 \\
\hline \multicolumn{6}{|c|}{ Tumor encapsulation } \\
\hline Present & 112 & & 70 & 42 & \\
\hline Absent & 53 & 0.162 & 24 & 29 & $0.037^{\ddagger}$ \\
\hline \multicolumn{6}{|l|}{ Tumor size } \\
\hline$\leq 7 \mathrm{~cm}$ & 97 & & 62 & 35 & \\
\hline$>7 \mathrm{~cm}$ & 69 & 0.174 & 32 & 37 & $0.025^{\ddagger}$ \\
\hline \multicolumn{6}{|c|}{ Microsatellite formation } \\
\hline Negative & 127 & & 76 & 51 & \\
\hline Positive & 38 & 0.106 & 18 & 20 & 0.173 \\
\hline \multicolumn{6}{|l|}{ Venous invasion } \\
\hline Negative & 142 & & 86 & 56 & \\
\hline Positive & 23 & 0.180 & 8 & 15 & $0.021^{\ddagger}$ \\
\hline \multicolumn{6}{|c|}{ Adjacent organs invasion } \\
\hline Negative & 120 & & 72 & 48 & \\
\hline Positive & 46 & 0.129 & 21 & 25 & 0.096 \\
\hline \multicolumn{6}{|l|}{ Tumor stage ${ }^{\S}$} \\
\hline Stage I-II & 114 & & 74 & 40 & \\
\hline Stage III-IV & 49 & 0.224 & 20 & 29 & $0.004^{\ddagger}$ \\
\hline \multicolumn{6}{|c|}{ Differentiation stage } \\
\hline Stage I-II & 93 & & 59 & 34 & \\
\hline Stage III-IV & 64 & 0.134 & 32 & 32 & 0.094 \\
\hline
\end{tabular}

*Summary of the clinicopathologic characteristics for PCR-based study series.

'Pearson's correlation coefficients.

ثSignificant correlation (Pearson $\chi^{2}$ test).

${ }^{\S}$ American Joint Committee on Cancer.

AFP, alpha-fetoprotein; Ag, antigen; HCC, hepatocellular carcinoma; MUC13, mucin 13.

expression level (defined as fold-change) of MUC13 $\left(2^{-\Delta \Delta \mathrm{Ct}}\right)$ was normalized to the endogenous 18SrRNA reference $(\Delta \mathrm{Ct})$ and related to the amount of target gene in the control sample, which was defined as the calibrator at 1.0. Three independent experiments were performed to analyze the relative gene expression, and each sample was tested in triplicate. The primer sequences are listed as following: MUC13, 5'-CCTTCGGTGTGATTATTATGGC-3' (forward) and 5'-GCATCTGGCTGTCTCTGGAG-3' (reverse); Axin2, 5'-AAGAGCCAAAGAAACTGGCA-3' (forward) and 5'-GCAAACTCATCGCTTGCTTT-3' (reverse); cMyc, 5'-TGGTGCTCCATGAGGAGACACC-3' (forward) and 5'-TGAGGACCAGTGGGCTGTGAGG-3' (reverse); cyclinD1, 5'-GTGGAACCTGGCCGCAATGA-3' (forward) and $5^{\prime}$-CACCATGGAGGGCGGATTGG-3' (reverse); 18S, 5'-CTCTTAGCTGAGTGTCCCGC-3' (forward) and 5'-CTGATCGTCTTCGAACCTCC-3' (reverse).

\section{Tissue Microarray and IHC}

Tissue microarray that contained 150 pairs of HCC tissues and matched nontumor tissues was constructed as described previously. ${ }^{23}$ None of the patients involved received preoperative treatment. Clinical samples used in this study were approved by the Committee for Ethical Review of Research at Sun Yat-Sen University. Immunohistochemistry (IHC) was performed with a standard streptavidin-biotin-peroxidase complex method to detect 
MUC13 and $\beta$-catenin expression. ${ }^{24}$ Sections were incubated with antibody to MUC13 (Abcam, Cambridge, MA) at a dilution of $1: 100$ or antibody to $\beta$-catenin (Cell Signaling Technology, Beverly, MA) at a dilution of 1:400. Staining was developed by diaminobenzidine according to the manufacturer, and the cell nucleus was stained with hematoxylin.

\section{Antibodies and Western Blot Analysis}

Western blot analyses were performed by the standard method with antibodies to MUC13 (Abcam); glyceraldehyde3-phosphate dehydrogenase (Santa Cruz Biotechnology, Dallas, TX); Axin2, c-Myc, $\beta$-catenin, phospho- $\beta$-catenin (Ser33/37/Thr41), phospho- $\beta$-catenin (Thr41/Ser45), phospho- $\beta$-catenin (Ser552), phospho- $\beta$-catenin (Ser675), E-cadherin, phospho-Akt (Ser473), Akt (pan), phospho-protein kinase A (PKA; Thr197), and PKA (Cell Signaling Technology, Danvers, MA). Intensities of bands were analyzed with the Macintosh densitometry program ImageJ software (NIH, Bethesda, MD; https://imagej.nih.gov/ij). Relative expression levels of MUC13 were normalized to expression of glyceraldehyde-3-phosphate dehydrogenase.

\section{IF Staining}

Immunofluorescence (IF) staining was performed as described previously. ${ }^{15}$ Briefly, cells were incubated with 1:100 dilution of antibody to $\beta$-catenin (Cell Signaling Technology) overnight at $4^{\circ} \mathrm{C}$. After rinsing three times, cells were incubated with 1:100 dilution of fluorescein isothiocyanate-conjugated goat anti-mouse IgG (Santa Cruz Biotechnology). Results were captured by fluorescence microscopy.

\section{Co-Immunoprecipitation}

Huh7 cells were lyzed with RIPA buffer that contained $0.5 \%$ Nonidet P- 40 . Whole-cell lysates were pretreated with Protein G plus agarose (Roche). Cell lysates were recovered and incubated with $2 \mu \mathrm{g}$ of the indicated primary antibody. Protein $G$ plus agarose was then added to bind the antibody-protein complex and incubated overnight. After rinsing three times, proteins were eluted with protein loading buffer and detected by the standard Western blot procedure.

\section{Statistical Analysis}

SPSS statistics 16.0 (SPSS Inc., Chicago, IL) was used for all data analyses. Statistical comparisons between two groups were performed by $t$-test. Multiple groups were analyzed by one-way analysis of variance, followed by the appropriate post hoc test to determine statistical significance. Clinical correlations of MUC13 RNA expression and clinicopathologic characteristics were analyzed by Pearson $\chi^{2}$ test. Survival was assessed by Kaplan-Meier plots and log-rank tests. Univariate and multivariate survival analyses were performed with the Cox proportional hazards regression model. Receiver operating characteristics (ROC) curves were used to assess the sensitivity and specificity of the survival predictions. $P<0.05$ was considered statistically significant.

\section{Results}

\section{MUC13 Is Frequently Up-Regulated in HCC}

Previous RNA sequencing data showed that MUC13 was overexpressed in all three tested HCC tumor tissues. ${ }^{3,4}$ Here, qPCR was applied to compare expression levels of MUC13 between tumor and corresponding adjacent nontumor tissues for $168 \mathrm{HCC}$ cases. MUC13 expression in tumor tissues was significantly higher than that in adjacent nontumor tissues $(P<0.001, t$-test) (Figure 1A). MUC13 protein expression level was also compared between tumor and matched nontumor tissues of 16 primary HCC samples. Although two protein bands were detected in nontumor samples and tumor samples, possibly because of glycosylation or dimerization of the protein, ${ }^{7,17}$ overexpression of MUC13 was clearly detected in neoplasms (Figure 1B). Five slides of paraffin sections of HCC patients were immunohistochemically stained for MUC13 expression. Overexpression of MUC13 (defined as relative expression MUC13/18S > 2) was detected in 74 of 168 HCC samples (44.0\%). Western blot analysis revealed that MUC13 was overexpressed in all HCC cell lines except SMMC7721, compared with immortalized normal liver cell lines MIHA and LO2 (Figure 1C). MUC13 expression in adjacent normal tissue was undetectable or showed faint staining (Figure 1D). However, tumor regions showed higher intensity staining of MUC13 in both cytoplasm and nucleus.

\section{Clinical Significance of MUC13 Overexpression}

The correlation between MUC13 expression status based on qPCR data and patients' clinicopathologic features was analyzed by Pearson $\chi^{2}$ test. Overexpression of MUC13 was significantly associated with tumor encapsulation $(P=0.037)$, tumor size $(P=0.025)$, tumor venous invasion $(P=0.021)$, and tumor stage $(P=0.004)$ (Table 1). Kaplan-Meier analysis and log-rank test showed that overexpression of MUC13 was significantly correlated with poorer OS $(P=0.019)$ but not with DFS $(P=0.147)$ of patients with HCC (Figure 1E). Univariate Cox regression analyses revealed that cirrhosis, tumor size, tumor thrombus, tumor grade, TNM stage, and MUC13 overexpression were significantly associated with OS of HCC patients (Supplemental Table S1). However, multivariate Cox proportional hazard regression analysis identified only cirrhosis and tumor grade as independent prognostic factors for OS of this HCC cohort (Supplemental Table S1). 

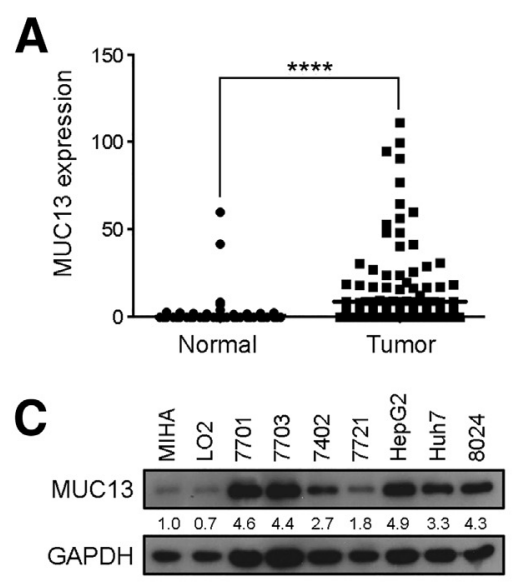

B
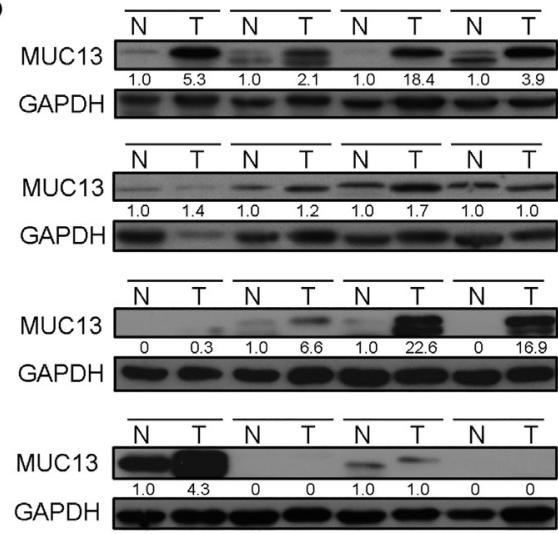

D
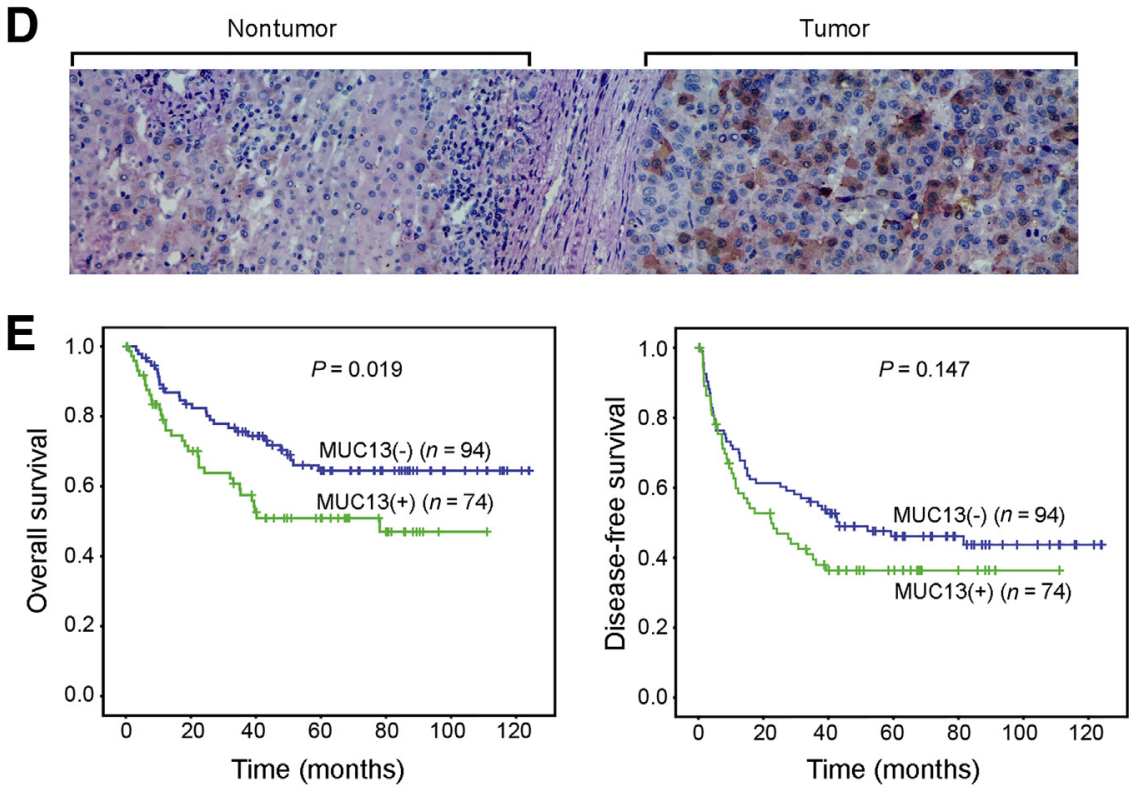

Figure 1 Mucin 13 (MUC13) is frequently upregulated in hepatocellular carcinoma (HCC) and associated with poor prognosis of HCC patients. A: Relative expression levels of MUC13 detected by quantitative RT-PCR in 168 paired samples of HCC tissue $(\mathrm{T})$ and matched nontumor $(\mathrm{N})$ tissue. Glyceraldehyde-3-phosphate dehydrogenase (GAPDH) was used as an internal control. B: Protein expression of MUC13 in 16 pairs of clinical HCC samples was compared by Western blot analysis. C: MUC13 expression in two immortalized liver cell lines (MIHA and L02) and seven HCC cell lines was detected by Western blot analysis. GAPDH was used as a loading control. Intensities of bands were analyzed with the Macintosh densitometry program ImageJ. Expression levels of MUC13 in different cell lines were normalized to that in MIHA. D: A representative immunohistochemical image (combination of multiple images) of MUC13 in primary HCC tissue and surrounding nontumor tissue. E: KaplanMeier analysis showing that the expression level of MUC13 in $168 \mathrm{HCC}$ patient samples is significantly associated with poorer overall survival (log-rank test) but not with disease-free survival (log-rank test). Statistical comparison was performed by independent $t$-test. ${ }^{* * *} P<0.0001$. Original magnification, $\times 400$ (D).

\section{MUC13 Has Strong Oncogenic Function}

To test the potential function of MUC13 in HCC, full-length MUC13 was stably transfected into LO2 and SMMC7721 cells, which express low levels of endogenous MUC13. Western blot analysis was performed to confirm protein expression (Figure 2A). Cell growth assays showed that transfection with $M U C 13$ effectively promoted growth rates of LO2 and SMMC7721 cells compared with transfection with empty vector $(P<0.001, t$-test) (Figure $2 \mathrm{~B})$. Foci formation assay showed that MUC13-transfected cells formed more clones than control cells $(P<0.05, t$-test $)$ (Figure 2C). In addition, MUC13 promoted cell invasive ability in the invasion assay $(P<0.05, t$-test) (Figure 2D). An in vivo tumorigenic assay was performed by subcutaneous injection of MUC13- and vector-transfected cells into right and left flanks of nude mice, respectively (LO2 cells in six mice, SMMC7721 in seven mice). Xenograft tumors were harvested after 4 weeks, and MUC13transfected cells developed larger tumors than control cells $(P<0.05, t$-test) (Figure 2E).
Silencing MUC13 by shRNAs Inhibits Its Oncogenic Ability

To further confirm the oncogenic function of $M U C 13$, its expression in Huh7 and PLC8024 cells was silenced by two specific shRNAs (shRNA2 and shRNA3). A nontargeting control shRNA was used as a negative control. Western blot analysis confirmed the silencing efficiency (Figure 3A). Functional studies revealed that silencing MUC13 in HCC cells markedly inhibited the cell growth rate $(P<0.05$, $t$-test) (Figure 3B), foci formation $(P<0.05, t$-test $)$ (Figure 3C), and invasive ability $(P<0.05, t$-test $)$ (Figure 3D). Silencing MUC13 also significantly inhibited in vivo tumorigenicity in the xenograft tumor formation assay $(P<0.01, t$-test) (Figure $3 \mathrm{E})$.

\section{MUC13 Promotes Cell $G_{1} / S$ Phase Transition}

Because MUC13 promoted cell growth, flow cytometry was applied to study the effect of MUC13 on the cell cycle. In LO2 cells, MUC13 decreased the percentage of cells in $\mathrm{G}_{1}$ 
A

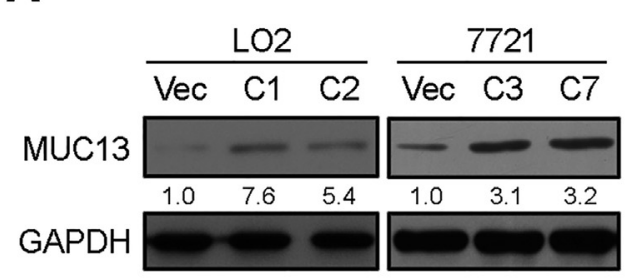

C

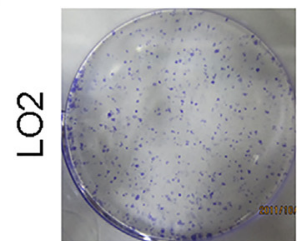

Vector

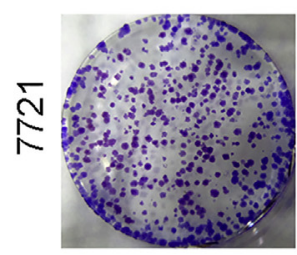

Vector

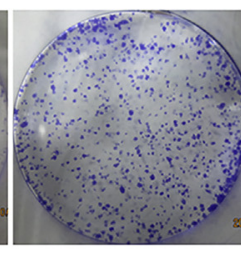

MUC13-C1

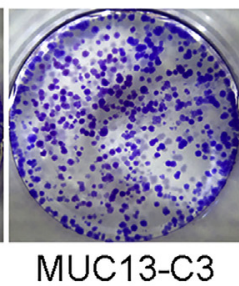

B

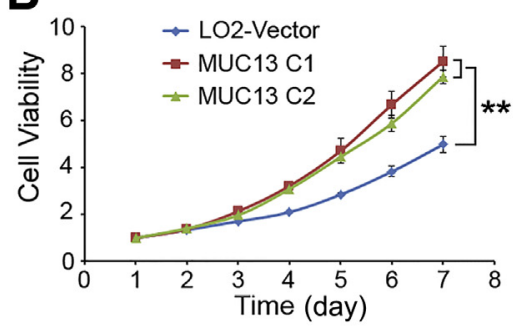

D

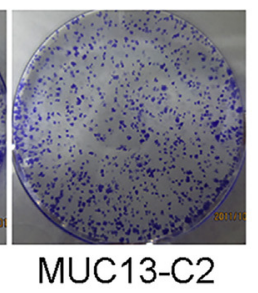

Оิ
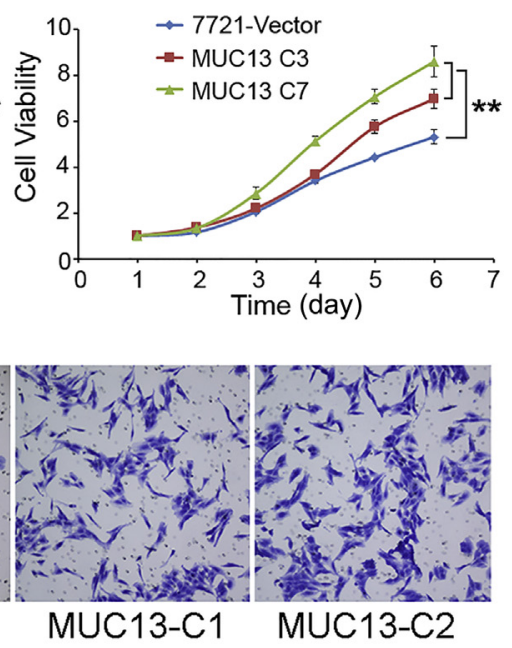
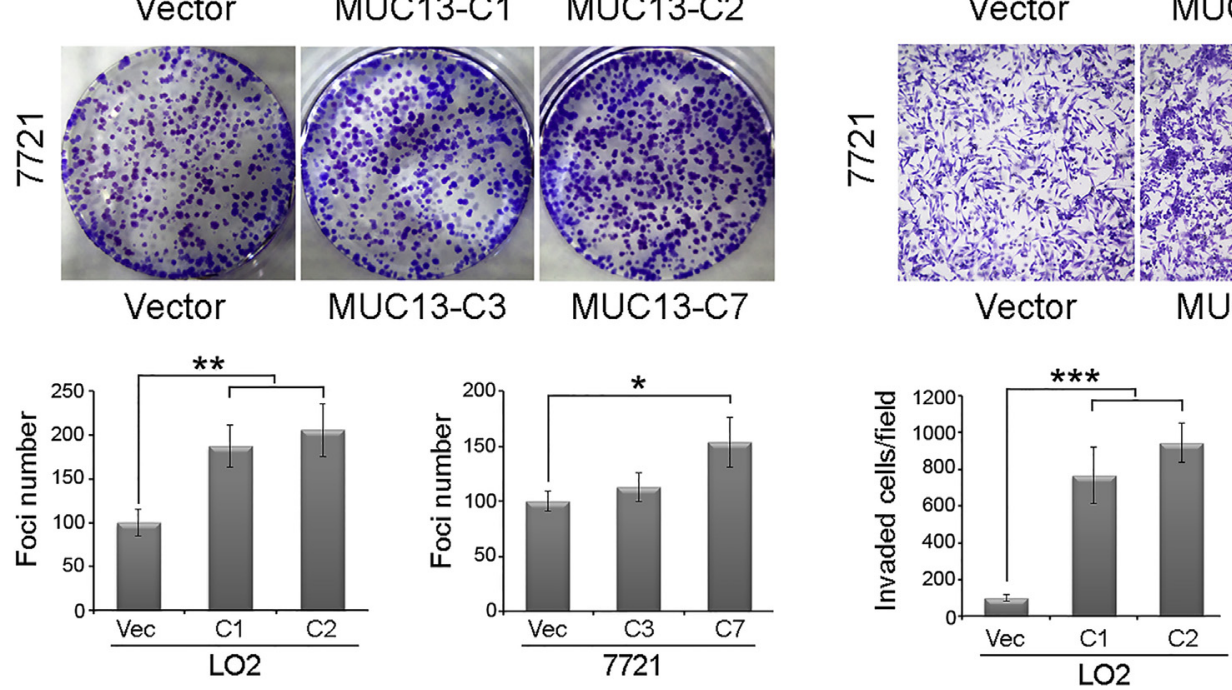

E

LO2
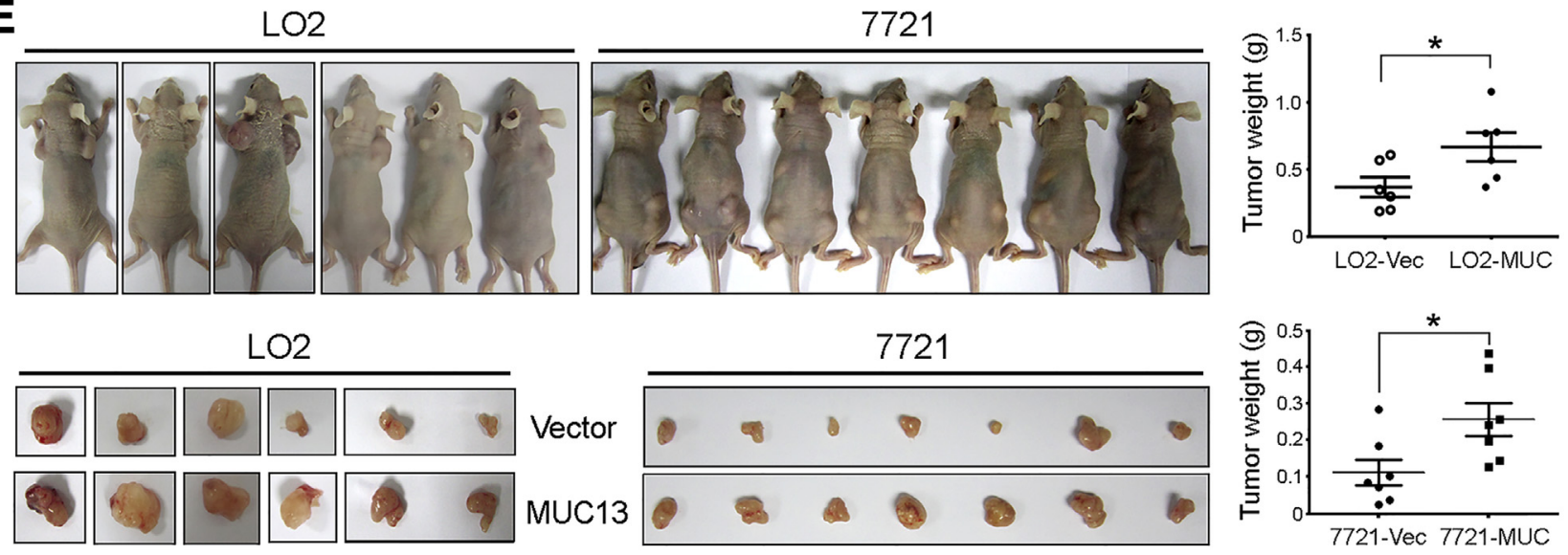

Figure 2 MUC13 has strong oncogenic ability. A: Expression of mucin 13 (MUC13) in MUC13-transfected L02 and SMMC7721 cells detected by Western blot analysis. Glyceraldehyde-3-phosphate dehydrogenase (GAPDH) was used as a loading control. Intensities of bands were analyzed by ImageJ. Expression levels of MUC13 were normalized to that in vector cells. B: Growth rates in L02 and SMMC7721 cells transfected with Muc13 and empty vector were compared with the CCK-8 kit (Tojindo, Shanghai, China). C: Upper panel shows representative images of raised foci formation in monolayer culture promoted by MUC13, compared with empty vector-transfected L02 and SMMC7721 cells, respectively. Lower panel summarizes foci formation. D: Upper panel shows representative images of the Matrigel invasion assay, with results summarized in the lower panel. E: Images of xenograft tumors (arrows) formed in nude mice injected with MUC13-transfected cells (right shoulder flank for L02 and right dorsal flank for SMMC7721) and empty vector-transfected cells (left shoulder flank for L02 and left dorsal flank for SMMC7721) are shown in the left panel. Tumor weights are summarized in the right panel. Results are expressed as the means \pm SD. $n=3$ independent experiments (B). ${ }^{*} P<0.05$, ${ }^{*} P<0.01$, and ${ }^{*} * P<0.001$, one-way analysis of variance or independent $t$-test. Original magnification: $\times 100$ (D). Vec, vector. 
A

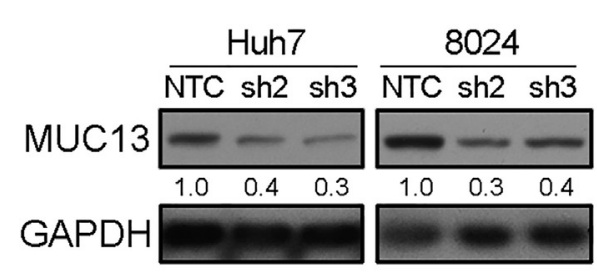

B

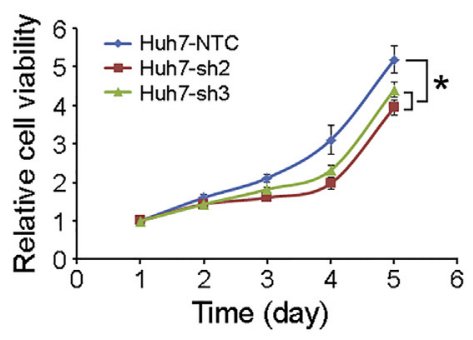

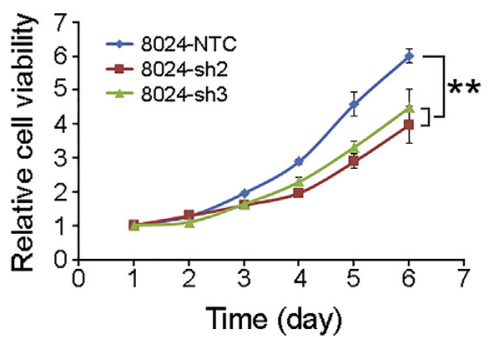

C
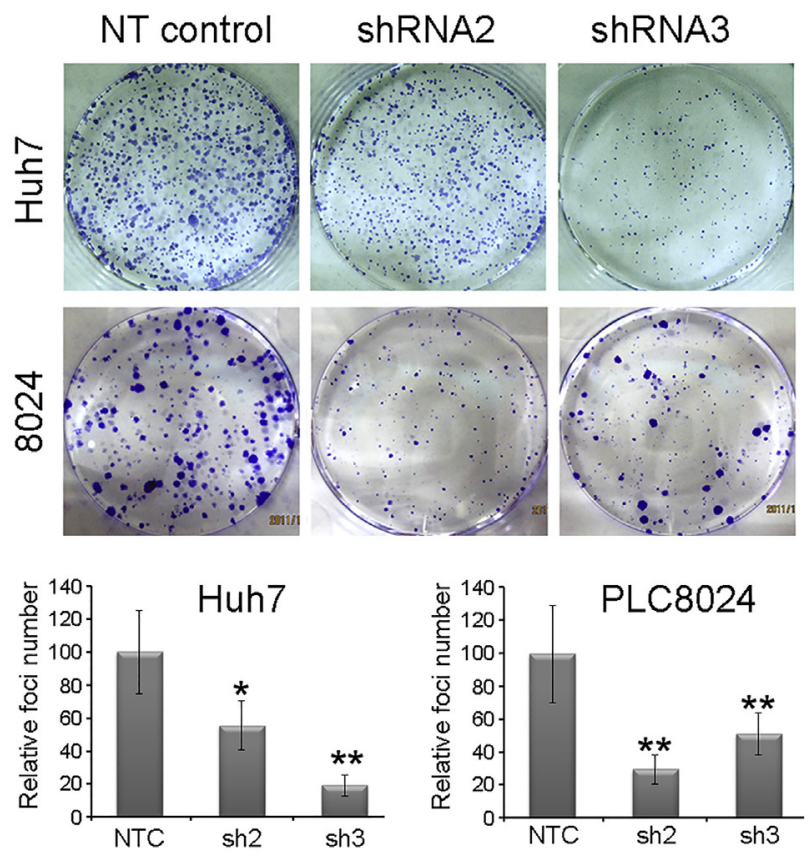

D
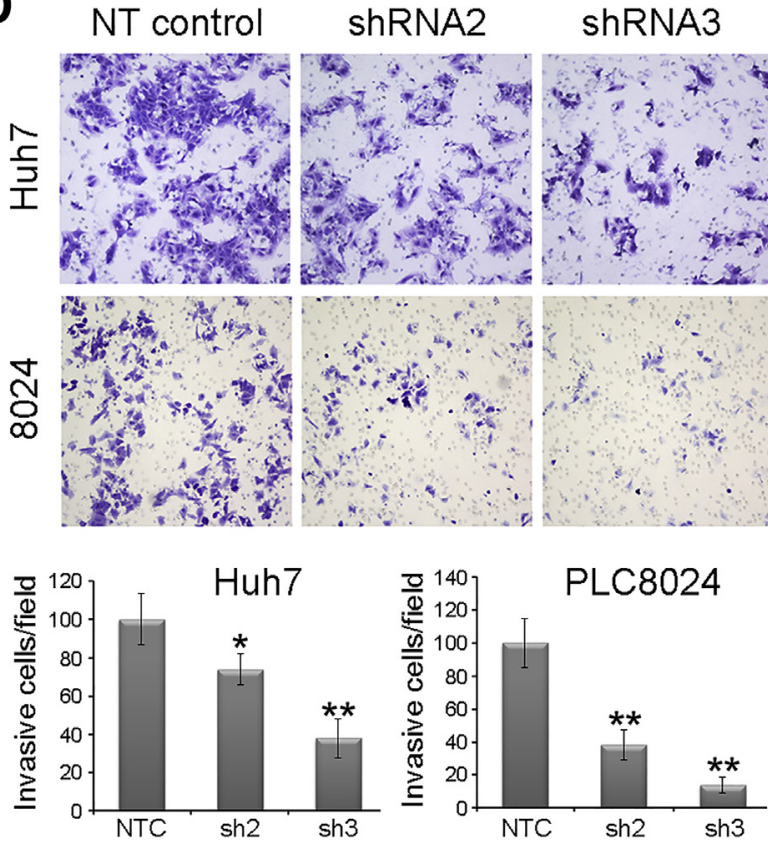

$\mathbf{E}$
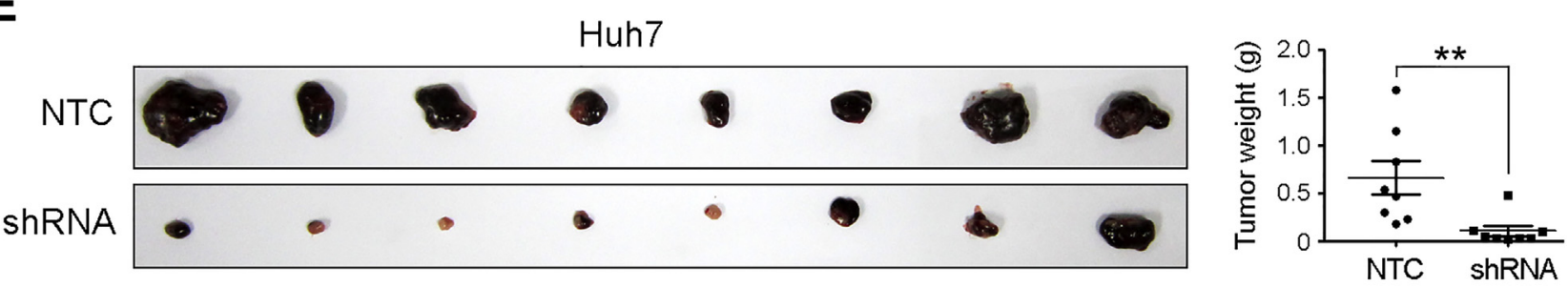

\section{PLC8024}
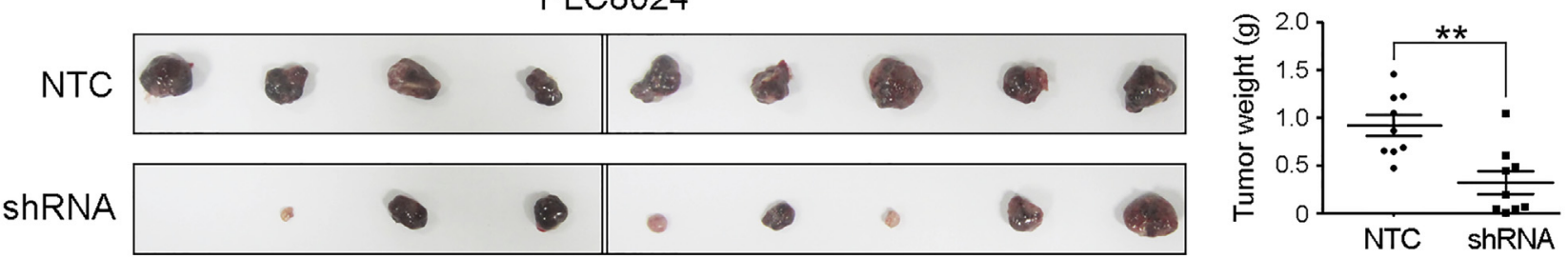

Figure 3 Knockdown of mucin 13 (MUC13) by shRNA inhibits its tumorigenic function. A: Western blot analysis of MUC13 expression in Huh7 and PLC8024 cells treated with two shRNAs targeting MUC13. Glyceraldehyde-3-phosphate dehydrogenase (GAPDH) was used as a loading control. Intensities of bands were analyzed by ImageJ. Expression levels of MUC13 were normalized to that in nontargeting control (NTC) cells. B-E: Silencing MUC13 in hepatocellular carcinoma (HCC) cell lines effectively inhibits cell growth (B), foci formation (C), cell invasion (D), and tumorigenicity (E) in nude mice. All results are expressed as the means \pm SD. $n=3$ independent experiments. ${ }^{*} P<0.05,{ }^{* *} P<0.01$, one-way analysis of variance or independent $t$-test. Original magnification: $\times 100$ (D). NT, nontargeting. 
A

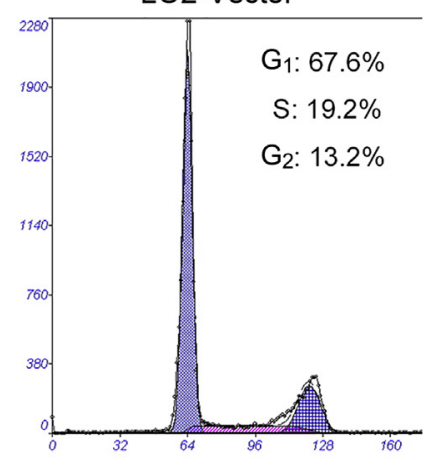

MUC13 C1

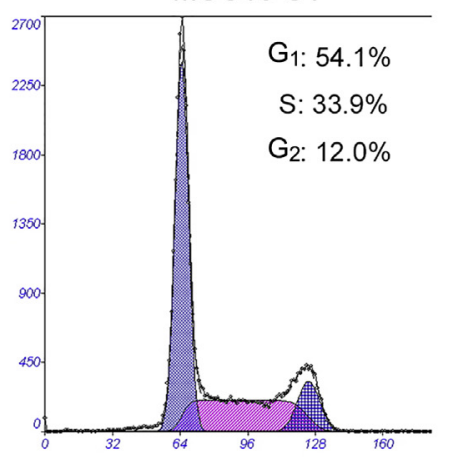

MUC13 C2

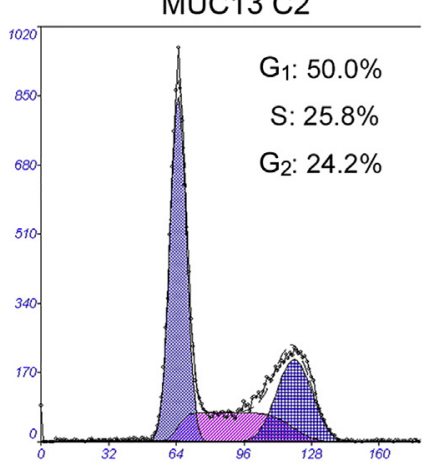

B

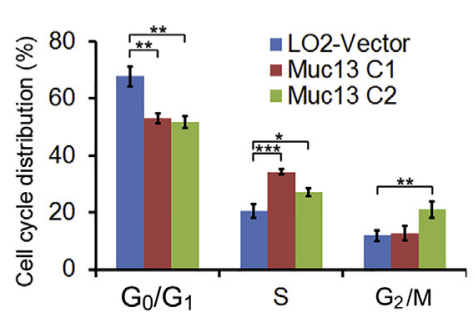

C

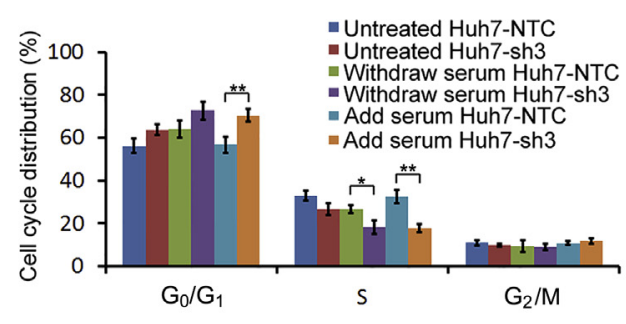

D
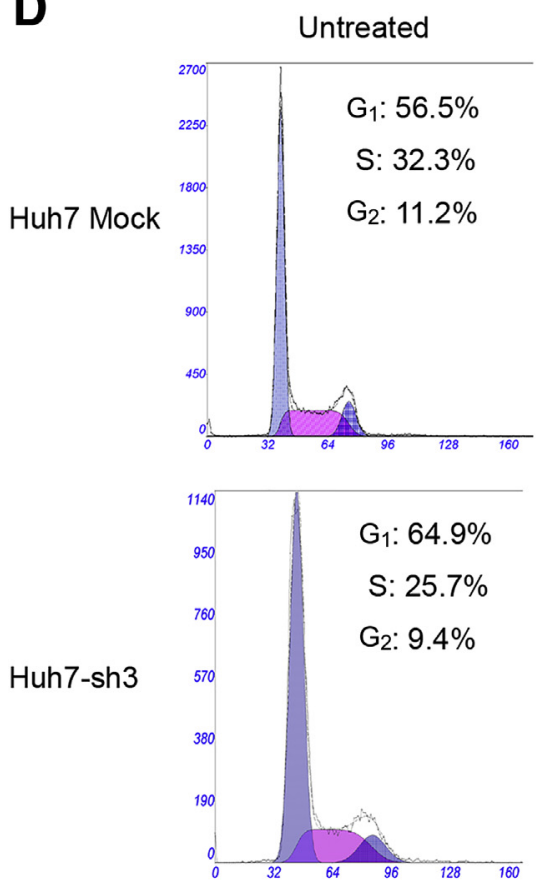
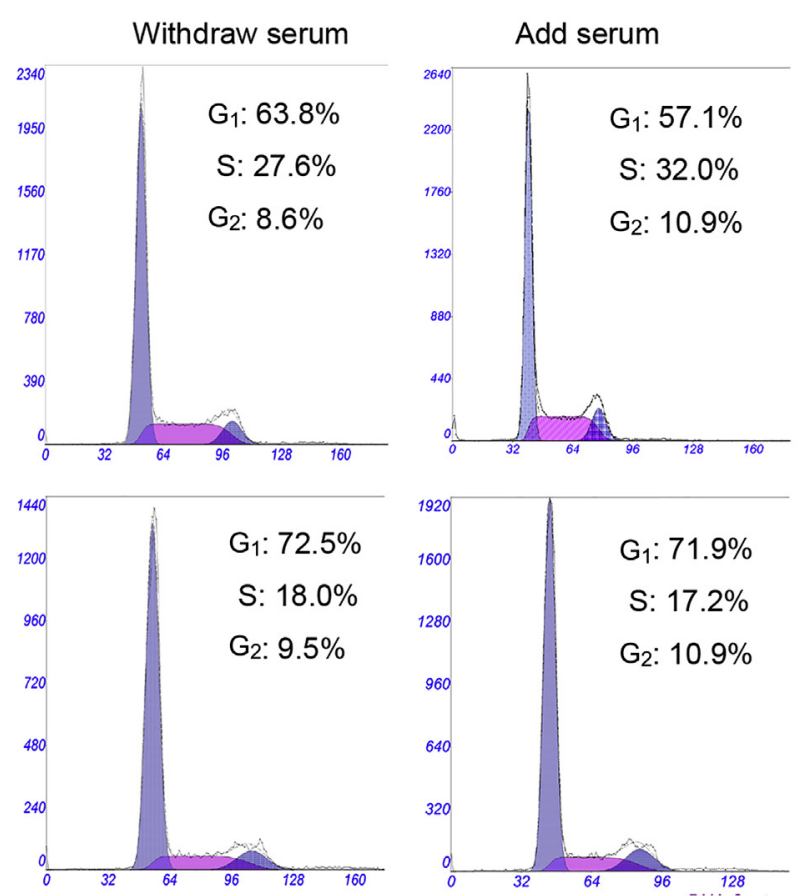

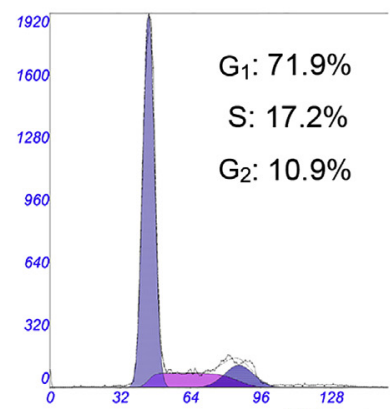

Figure 4 Mucin 13 (MUC13) promotes $\mathrm{G}_{1} / \mathrm{S}$ transition. A: Representative images of cell cycle distribution detected by flow cytometry in cells transfected with MUC13 and empty vector. B: Histogram showing a significantly greater number of cells at the S phase in L02 cells with MUC13 overexpression than with blank vector cells, whereas the number of cells in $G_{0} / G_{1}$ phase is much lower. $C$ and $\mathbf{D}$ : The number of cells in $S$ phase is significantly reduced in Huh7 cells with MUC13 knockdown compared with mock cells when serum was added back after culture without serum. Untreated cells were cultured in Dulbecco's modified Eagle's medium (DMEM) with 10\% fetal bovine serum (FBS). For serum withdrawal, cells were cultured in DMEM without serum for 3 days before addition of serum and further culture in DMEM with $10 \%$ FBS for 12 hours. ${ }^{*} P<0.05$, ${ }^{*} P<0.01$, and ${ }^{* * *} P<0.001$, one-way analysis of variance. NTC, nontargeting control.

phase and increased the percentage in $\mathrm{S}$ phase $(P<0.05$, $t$-test) (Figure 4, A and B). In Huh7 cells, MUC13 silencing inhibited the $\mathrm{G}_{1} / \mathrm{S}$ transition. At 12 hours after the addition of fetal bovine serum to synchronized cells grown in serum- free medium, the percentage of cells in $\mathrm{S}$ phase was markedly decreased in sh-MUC13-treated cells compared with scramble shRNA-treated cells $(P<0.05, t$-test) (Figure 4, C and D). 
A
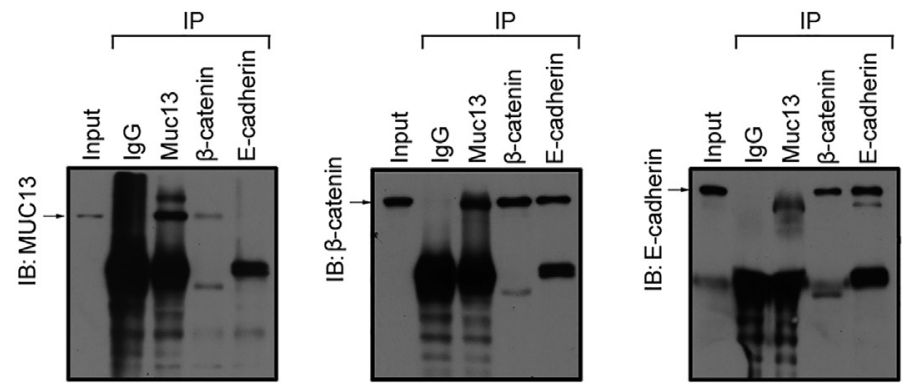

B

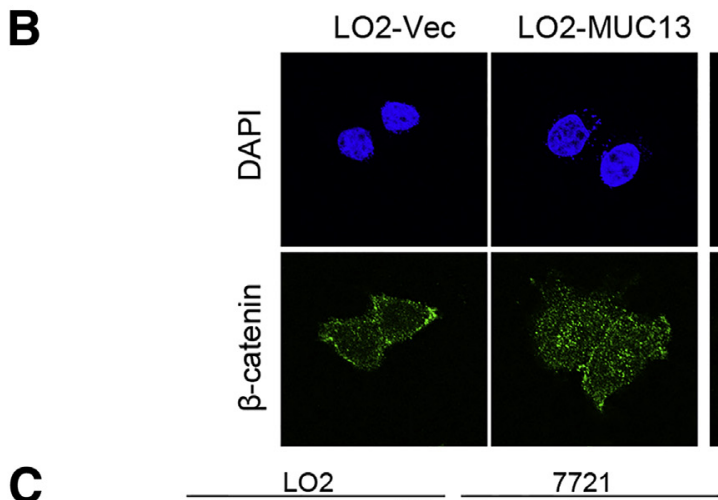

$7721-\mathrm{Vec}$

7721-MUC13

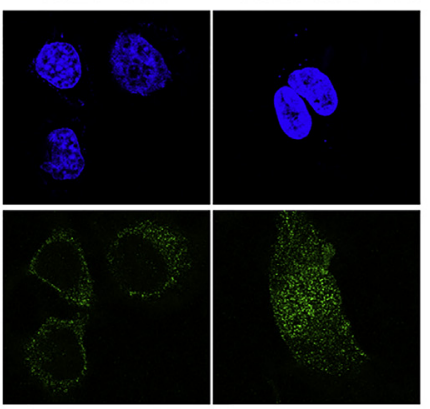

C
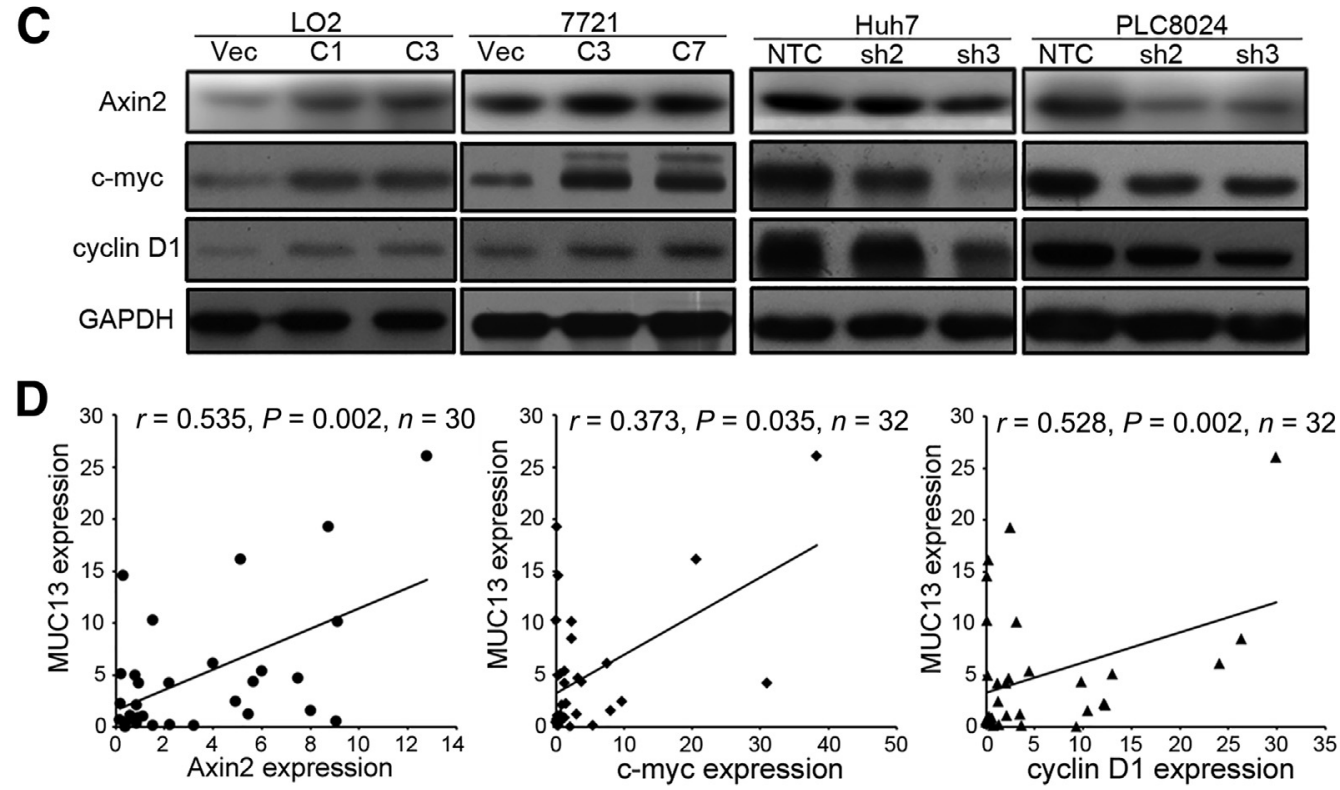

Figure 5 Mucin 13 (MUC13) binds to $\beta$-catenin, promotes its nuclear translocation, and up-regulates Axin2, c-Myc, and cyclinD1 expression. A: Lysates from Huh7 cells were immunoprecipitated with anti-MUC13, anti- $\beta$-catenin, and anti-E-cadherin antibodies, with normal IgG as negative control. Whole cell lysates were loaded as a positive immunoblotting (IB) control (Input). The precipitates were analyzed by immunoblotting with anti-MUC13, anti- $\beta$-catenin, and anti-E-cadherin antibodies. Endogenous co-immunoprecipitation (co-IP) analysis shows that MUC13 binds to $\beta$-catenin. E-cadherin was used as a positive control for $\beta$-catenin binding. B: Representative immunofluorescence images showing nuclear translocation of $\beta$-catenin in MUC13-transfected cells compared with empty vector (VEC)-transfected cells. Nuclei were counterstained with DAPI. C: Western blot analysis shows that the expression of Axin2, c-Myc, and cylinD1 is up-regulated in MUC13-transfected cells compared with empty vector-transfected cells (left panel) and down-regulated in shRNA-MUC13 cells compared with mock cells (right panel). D: Linear regression and significant Pearson correlation of MUC13 with Axin2, c-Myc, and cyclinD1 in clinical hepatocellular carcinoma samples by quantitative RT-PCR analysis. Original magnification: $\times 1000$ (B) GAPDH, glyceraldehyde-3-phosphate dehydrogenase.

\section{MUC13 Binds to $\beta$-Catenin and Activates Wnt Signaling}

MUC1, another member of the mucin family, can bind to $\beta$-catenin and cause its cellular translocation from cytoplasm to nucleus. ${ }^{25}$ Because there is a high level of homology between MUC1 and MUC13, ${ }^{26,27}$ we hypothesized that
MUC13 might bind to $\beta$-catenin and activate the Wnt signaling pathway. In co-immunoprecipitation experiments MUC13 was able to pull-down $\beta$-catenin and vice versa (Figure 5A). To investigate whether MUC13 promoted membrane to nuclear translocation of $\beta$-catenin, IF staining was performed with anti- $\beta$-catenin antibody in MUC13- 


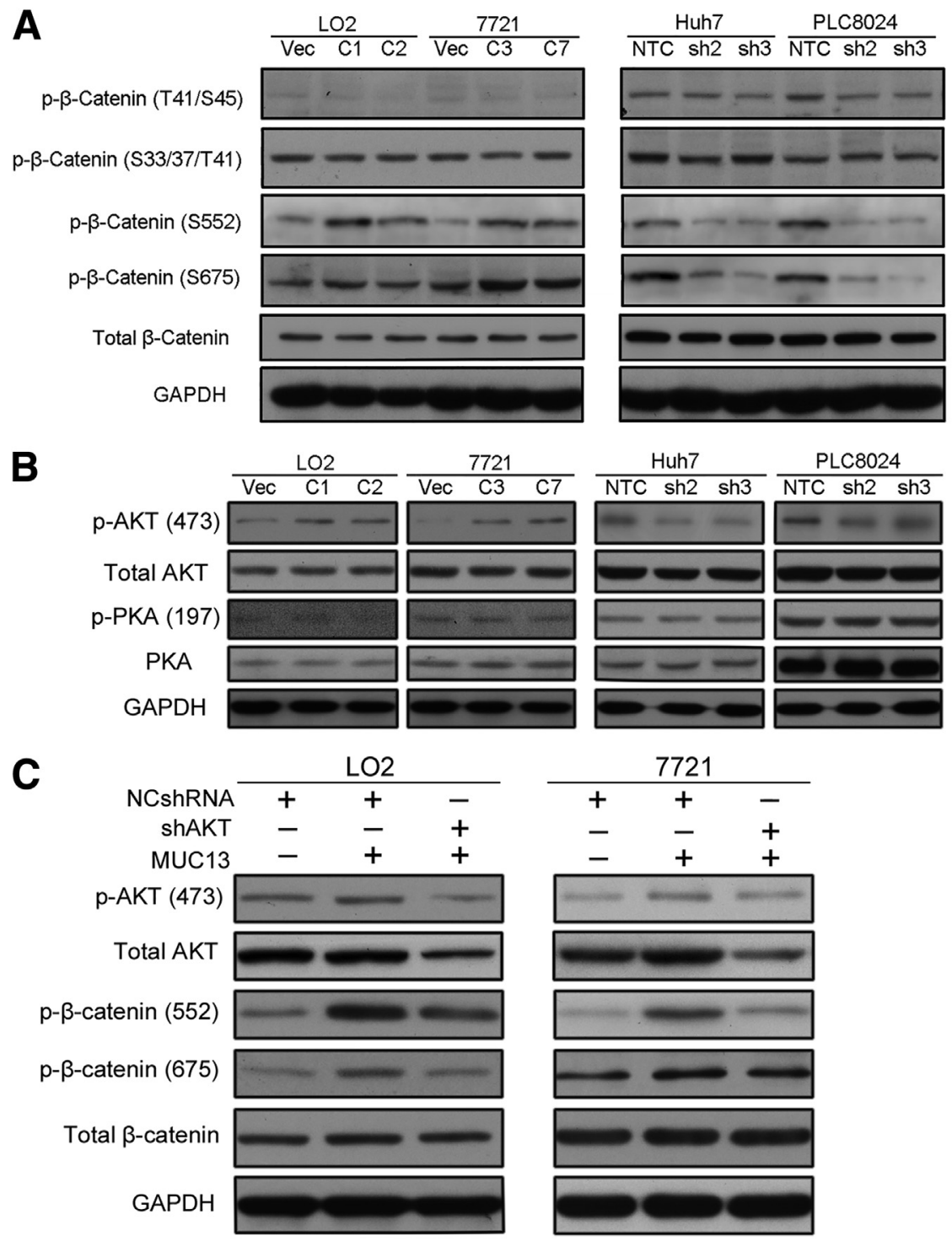

Figure 6 Mucin 13 (MUC13) regulates $\beta$-catenin phosphorylation by AKT signaling. A: Phosphorylation levels of $\beta$-catenin at Ser552 and Ser675 are increased in MUC13-transfected cells compared with empty vector (VEC)-transfected cells and decreased in MUC13-silenced cells. No obvious change is observed in the phosphorylation levels of $\beta$-catenin at Thr41/Ser45 or Ser33/37/ Thr41 or in total $\beta$-catenin. B: AKT kinase activity [phosphor-AKT(Ser473)] is up-regulated in MUC13-transfected cells compared with empty vector-transfected cells and decreased in MUC13silenced cells. No change is found for protein kinase A (PKA) kinase activity [phosphor-PKA (Thr197)]. C: Enhanced phosphorylation of $\beta$-catenin by MUC13 is abrogated by AKT shRNA (shAKT) in both L02 and SMMC7721. Glyceraldehyde-3-phosphate dehydrogenase (GAPDH) was used as a loading control. NTC, nontargeting control.

transfected cells. As expected, MUC13 promoted $\beta$-catenin translocation from membrane to nucleus (Figure 5B). Next, Western blot analysis was applied to study whether downstream targets of $\beta$-catenin (eg, Axin2, CyclinD1, and c-Myc) were up-regulated by MUC13. Expression levels of Axin2, CyclinD1, and c-Myc were up-regulated in MUC13transfected cells compared with control cells (Figure 5C) and dramatically down-regulated when MUC13 was silenced (Figure 5C). The correlation of MUC13 expression with Axin2, c-Myc, and cyclinD1 in clinical samples was further studied by qPCR in another cohort of 32 HCC cases. Expression of MUC13 significantly correlated with expression of Axin2 $(r=0.535, P<0.01)$, c-Myc $(r=0.373$, $P<0.05$ ), and CyclinD1 ( $r=0.528, P<0.01$ ) (Figure 5D). These results indicated that MUC13 activated Wnt signaling through promotion of $\beta$-catenin nuclear translocation and subsequently up-regulated Axin2, c-Myc, and cyclinD1.
MUC13 Enhances $\beta$-Catenin Phosphorylation at Ser552 and Ser675

The subcellular location of $\beta$-catenin is closely correlated to its phosphorylation status. ${ }^{28}$ The role of MUC13 in $\beta$-catenin phosphorylation was studied next. Western blot analysis showed that the phosphorylation level of $\beta$-catenin at Ser552 and Ser675, which is associated with its nuclear translocation, was enhanced in MUC13-transfected cells and decreased in MUC13-silenced cells (Figure 6A). No obvious change was observed in Ser45, Thr41, Ser37, and Ser33 phosphorylation sites of $\beta$-catenin that are responsible for its cytoplasmic location (Figure 6A).

Phosphorylation of $\beta$-catenin at Ser552 and Ser675 was regulated by the AKT and PKA signaling pathways. ${ }^{29,30}$ It was questioned whether these signaling pathways played a role in MUC13 stimulating $\beta$-catenin phosphorylation. 
A
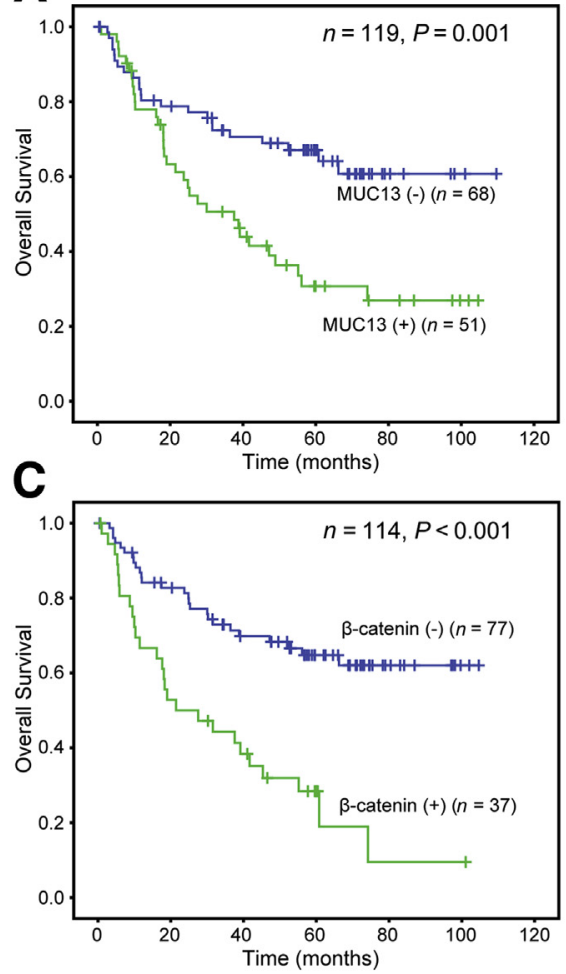

E

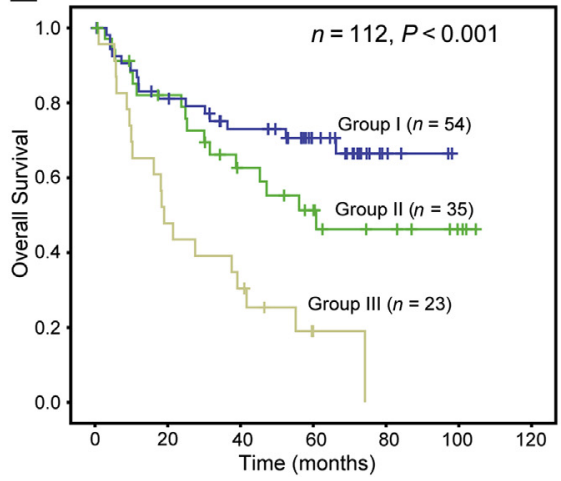

B
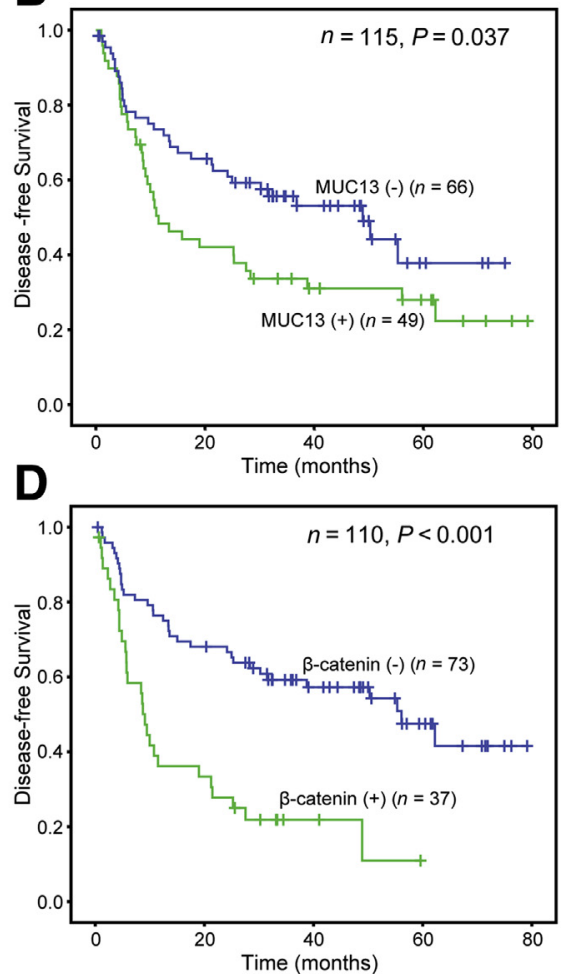

$\mathbf{F}$

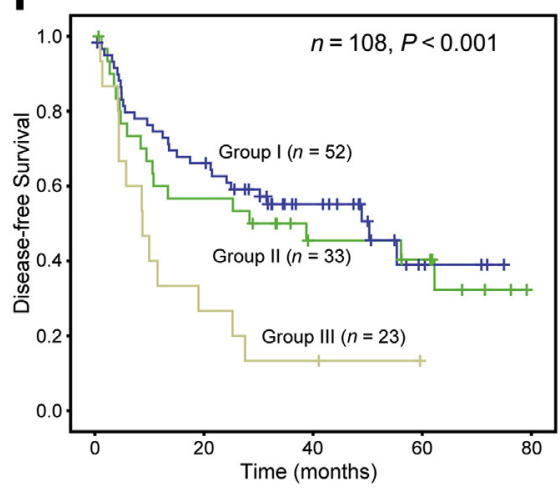

Figure 7 Mucin 13 (MUC13) and $\beta$-catenin expression predict poor survival in hepatocellular carcinoma (HCC) patients. A and B: Kaplan-Meier analysis showing that overexpression of MUC13 is significantly associated with poorer overall survival (OS) and disease-free survival (DFS) in HCC patients (log-rank test). $\mathbf{C}$ and $\mathbf{D}$ : Nuclear $\beta$-catenin expression correlates with unfavorable OS and DFS in HCC patients by Kaplan-Meier analysis (log-rank test). $\mathbf{E}$ and $\mathbf{F}$ : Kaplan-Meier curves of OS and DFS in HCC patients classified according to MUC13 expression status and $\beta$-catenin nuclear location. Patients with both MUC13 overexpression and nuclear $\beta$-catenin expression (group III) have poorer survival outcome than patients with either MUC13 overexpression or $\beta$ catenin nuclear expression (group II) and patients without expression of either protein (group I). Moreover, patients in group I have worse OS and DFS survival rates than patients in group II (logrank test). MUC13 $(+)$, positive group for MUC13 overexpression; MUC13 $(-)$, negative group for MUC13 overexpression; $\beta$-catenin $(+)$, positive group for nuclear $\beta$-catenin expression; $\beta$-catenin $(-)$, negative group for nuclear $\beta$-catenin expression.
Western blot analysis showed that phosphorylated AKT was up-regulated in MUC13-transfected cells and downregulated in $M U C 13$-silenced cells, whereas no significant change was observed for phosphorylated PKA (Figure 6B). By shRNA, AKT was interfered in MUC13-overexpressing cells. MUC13-enhanced phosphorylation of $\beta$-catenin was markedly abrogated by shAKT in both LO2 and 7721 (Figure 6C). These results suggested that AKT-mediated MUC13 enhanced phosphorylation of $\beta$-catenin.

\section{Combination of MUC13 and $\beta$-Catenin Expression Predicts Poor Survival in HCC Patients}

To further explore the clinical significance of MUC13 overexpression and $\beta$-catenin nuclear localization in $\mathrm{HCC}$ patients, IHC was applied to determine the expression of the two proteins in a constructed tissue microarray that contained 150 pairs of HCC tumor tissues and matched nontumor tissues. Overexpression of MUC13 was detected in 51 of 119 informative HCCs $(42.9 \%)$ compared with their paired nontumor liver tissues. Noninformative cases were caused by sample loss in either nontumor or tumor spots. Interestingly, overexpression of MUC13 was significantly associated with hepatitis B virus (HBV) DNA copy number $(P=0.036$, Supplemental Table S2), poor OS rate $(P=0.001)$, and poor DFS rate $(P=0.037)$ (Figure $7, \mathrm{~A}$ and $\mathrm{B})$. Nuclear location of $\beta$-catenin was detected in 37 of 114 informative HCCs $(32.5 \%)$ and was also associated with poor OS $(P<0.001)$ and DFS $(P<0.001)$ time in HCC patients (Figure 7, C and D).

Because nuclear location of $\beta$-catenin was significantly associated with MUC13 overexpression ( $r=0.333$ and $P<0.001$ ) (Supplemental Table S2), it was next investigated 
Table 2 Multivariate Analyses of Factors Associated with OS and DFS

\begin{tabular}{|c|c|c|c|c|}
\hline \multirow[b]{2}{*}{ Clinicopathologic features } & \multicolumn{2}{|l|}{ OS } & \multicolumn{2}{|l|}{ DFS } \\
\hline & $\mathrm{HR}(95 \% \mathrm{CI})$ & $P$ & $\mathrm{HR}(95 \% \mathrm{CI})$ & $P$ \\
\hline $\operatorname{AFP}(\leq 400$ versus $>400)$ & $2.167(1.176-3.994)$ & $0.013^{*}$ & $1.617(0.931-2.807)$ & 0.088 \\
\hline Microsatellite formation (absent versus present) & $1.320(0.683-2.551)$ & 0.409 & $1.592(0.886-2.862)$ & 0.120 \\
\hline Tumor size $(\geq 7 \mathrm{~cm}$ versus $<7 \mathrm{~cm})$ & $1.842(0.984-3.446)$ & 0.056 & $1.598(0.917-2.786)$ & 0.098 \\
\hline Tumor thrombus (absent versus present) & $4.155(1.871-9.228)$ & $<0.001$ * & $3.222(1.536-6.758)$ & $0.002 *$ \\
\hline
\end{tabular}

*Significant difference of HR between the two groups (Cox regression).

AFP, alpha-fetoprotein; DFS, disease-free survival; HR, hazard ratio; MUC13, mucin 13; OS, overall survival.

whether it enhanced the predictive power of MUC13 overexpression. Patients were divided into three groups: group I with neither MUC13 overexpression nor nuclear $\beta$-catenin expression; group II with either MUC13 overexpression or nuclear $\beta$-catenin expression; and group III with both MUC13 overexpression and nuclear $\beta$-catenin expression. Patients in group III had the most unfavorable OS and DFS rates compared with group I and group II, whereas group II patients had poorer OS and DFS rates than group I patients $(P<0.001)$ (Figure 7, E and F; Supplemental Table S3). In addition, multivariate analysis indicated that the combination of MUC13 overexpression and nuclear $\beta$-catenin expression was an independent predictor of both OS $(P<0.001)$ and DFS $(P<0.001)$ (Table 2$)$. ROC curves were also generated to evaluate the sensitivity and specificity of the predictors, showing that these two factors combined had better predictive power for survival than either factor alone (Supplemental Figure S1, A and B).

\section{Discussion}

Transmembrane mucins have been found to play important roles in cancer development and progression by affecting cell growth, tumor invasion, and survival. ${ }^{26}$ Overexpression of MUC13 has been reported in various solid tumors, including gastric, colorectal, pancreatic, ovarian, esophageal, and renal cancers. ${ }^{7-16}$ Here, we found that overexpression of MUC13 was frequently detected in HCC cases and was significantly associated with tumor encapsulation, tumor size, venous invasion, and tumor stage. Consistent with the results in colon, gastric, and renal cancers, overexpression of MUC13 may be used as a prognostic factor to predict poorer outcome of HCC patients.

MUC13 was shown to have the ability to promote cell proliferation and invasion ${ }^{17,19,20,31}$ and to protect cells from death. ${ }^{31}$ Here, we demonstrated that $M U C 13$ possessed strong oncogenic ability in HCC using in vitro and in vivo assays. Overexpression of MUC13 in LO2 and SMMC7721 promoted cell growth and migration and induced tumor formation in nude mice. Silencing of MUC13 in Huh7 and PLC8024 by RNAi markedly inhibited its pro-oncogenic effect. Further study demonstrated MUC13 may promote cell cycle progression by increasing the transition from $\mathrm{G}_{1}$ to $\mathrm{S}$ phase. In addition, Western blot analysis indicated that two important $\mathrm{G}_{1} / \mathrm{S}$ regulation factors, c-Myc and cyclinD1, were upregulated by MUC13. In clinical samples, expression levels of c-Myc and cyclinD1 were positively correlated with MUC13 expression. Together, these results indicated that the oncogenic effect of MUC13 might be mediated through promotion of transition from $\mathrm{G}_{1}$ to $\mathrm{S}$ phase by up-regulation of $\mathrm{c}$ Myc and cyclinD1.

Axin2 expression was also changed in MUC13overexpressing and -silenced cells. Axin2, c-Myc, and cyclinD1 are transcriptionally activated by the $\mathrm{Wnt} / \beta$-catenin signaling pathway. ${ }^{28}$ Meanwhile, MUC1 binds to $\beta$-catenin and modulates its localization. ${ }^{32}$ Nuclear association of the cytoplasmic tail of MUC1 and $\beta$-catenin was also observed in pancreatic cancer cells. ${ }^{33}$ Interestingly, MUC13 has a 69-amino acid cytoplasmic tail that includes five potential serine phosphorylation sites, ${ }^{6}$ raising the possibility that MUC13 can bind to $\beta$-catenin and promote its nuclear translocation. To explore the molecular mechanism by which MUC13 up-regulates Axin2, c-Myc, and cyclinD1, the interaction between MUC13 and $\beta$-catenin was characterized by co-immunoprecipitation assay, confirming the interaction of MUC13 with $\beta$-catenin. In addition, IF data clearly indicated that MUC13 promoted $\beta$-catenin translocation from the cytoplasm to nucleus. However, which domain of MUC13 particularly interacts with $\beta$-catenin remains to be further studied.

The phosphorylation status of $\beta$-catenin because of the action of different proteins has been closely correlated to its subcellular location. Sequential phosphorylation of $\beta$ catenin at Ser45, Thr41, Ser37, and Ser33 regulated by CK1, Axin, GSK-3B, and APC causes ubiquitin-dependent degradation of $\beta$-catenin and blocks its nuclear translocation. ${ }^{34}$ In contrast, phosphorylation of $\beta$-catenin at Ser552 and Ser675 regulated by the AKT and PKA signaling pathway leads to accumulation of $\beta$-catenin in the cytoplasm and causes its nuclear translocation. ${ }^{29,30}$ Nuclear $\beta$-catenin forms complexes with members of the T-cell factor/lymphoid-enhancing factor family of DNA binding proteins and thereby modulates transcription of numerous target genes, including Axin2, c-Myc, cyclinD1, matrix metalloproteinase 7 , and E-cadherin. ${ }^{34}$ Phosphorylation 
levels of $\beta$-catenin at Ser552 and Ser675 sites were enhanced in MUC13-transfected cells. In addition, MUC13 regulated the protein kinase activity of AKT but not PKA. Knockdown of AKT in MUC13-overexpressing cells abrogated the phosphorylation of $\beta$-catenin at Ser552 and Ser675, which was enhanced by MUC13. These data indicated that MUC13 increased AKT kinase activity, which might result in nuclear translocation of $\beta$-catenin by elevating its Ser552 and Ser675 phosphorylation, and caused up-regulation of its downstream target genes. Concerning the direct interaction of MUC13 and $\beta$-catenin, how AKT mediates the regulation of $\beta$-catenin phosphorylation by MUC13 requires further study.

The relationship between MUC13 and $\beta$-catenin was further confirmed in clinical samples by IHC. Nuclear location of $\beta$-catenin was significantly associated with MUC13 overexpression $(P=0.001)$. In addition, both Kaplan-Meier analysis and ROC analysis indicated that the combination of the above two factors had superior prognostic predictive power than either factor alone. Furthermore, the co-index of MUC13 overexpression and nuclear location of $\beta$-catenin was an independent prognosticator for both OS and DFS in multivariate analysis.

\section{Conclusion}

Our results proved that overexpression of MUC13 promoted cell growth and predicted poor prognosis by activating the Wnt signaling pathway.

\section{Acknowledgments}

Y.D., L.L., T.Z., and X.-Y.G. conceptualized the study; Y.D., L.L., and T.Z. designed the methodology; Y.D., L.L., T.Z., J.-Z.L., Y.S., and K.C. acquired the data; Y.D., L.L., T.Z., and X.-Y.G. analyzed data; Y.D., L.L., and X.-Y.G. wrote and reviewed the manuscript; T.Z., J.-Z.L., Y.S., K.C., Y.L., L.C., Y.-H.Z., J.L., Y.L., D.X., and Y.-F.Y. provided administrative, technical, and material support; and X.-Y.G. supervised the study.

\section{Supplemental Data}

Supplemental material for this article can be found at https://doi.org/10.1016/j.ajpath.2017.10.016.

\section{References}

1. Farazi PA, DePinho RA: Hepatocellular carcinoma pathogenesis: from genes to environment. Nat Rev Cancer 2006, 6:674-687

2. Thorgeirsson SS, Grisham JW: Molecular pathogenesis of human hepatocellular carcinoma. Nat Genet 2002, 31:339-346

3. Chen L, Li Y, Lin CH, Chan TH, Chow RK, Song Y, Liu M, Yuan YF, Fu L, Kong KL, Qi L, Zhang N, Tong AH, Kwong DL, Man K, Lo CM, Lok S, Tenen DG, Guan XY: Recoding RNA editing of
AZIN1 predisposes to hepatocellular carcinoma. Nat Med 2013, 19: 209-216

4. Song Y, Pan G, Chen L, Ma S, Zeng T, Man Chan TH, Li L, Lian Q, Chow R, Cai X, Li Y, Liu M, Zhu Y, Wong N, Yuan YF, Pei D, Guan XY: Loss of ATOH8 increases stem cell features of hepatocellular carcinoma cells. Gastroenterology 2015, 149:1068-1081.e5

5. Mantelli F, Argueso P: Functions of ocular surface mucins in health and disease. Curr Opin Allergy Clin Immunol 2008, 8:477-483

6. Williams SJ, Wreschner DH, Tran M, Eyre HJ, Sutherland GR, McGuckin MA: Muc13, a novel human cell surface mucin expressed by epithelial and hemopoietic cells. J Biol Chem 2001, 276: 18327-18336

7. Shimamura T, Ito H, Shibahara J, Watanabe A, Hippo Y, Taniguchi H, Chen Y, Kashima T, Ohtomo T, Tanioka F, Iwanari H, Kodama T, Kazui T, Sugimura H, Fukayama M, Aburatani H: Overexpression of MUC13 is associated with intestinal-type gastric cancer. Cancer Sci 2005, 96:265-273

8. Lee HJ, Nam KT, Park HS, Kim MA, Lafleur BJ, Aburatani H, Yang HK, Kim WH, Goldenring JR: Gene expression profiling of metaplastic lineages identifies $\mathrm{CDH} 17$ as a prognostic marker in early stage gastric cancer. Gastroenterology 2010, 139:213-225.e3

9. Suh YS, Lee HJ, Jung EJ, Kim MA, Nam KT, Goldenring JR, Yang HK, Kim WH: The combined expression of metaplasia biomarkers predicts the prognosis of gastric cancer. Ann Surg Oncol 2012, 19:1240-1249

10. Walsh MD, Young JP, Leggett BA, Williams SH, Jass JR, McGuckin MA: The MUC13 cell surface mucin is highly expressed by human colorectal carcinomas. Hum Pathol 2007, 38:883-892

11. Gupta BK, Maher DM, Ebeling MC, Sundram V, Koch MD, Lynch DW, Bohlmeyer T, Watanabe A, Aburatani H, Puumala SE, Jaggi M, Chauhan SC: Increased expression and aberrant localization of mucin 13 in metastatic colon cancer. J Histochem Cytochem 2012, 60:822-831

12. Chauhan SC, Ebeling MC, Maher DM, Koch MD, Watanabe A, Aburatani H, Lio Y, Jaggi M: MUC13 mucin augments pancreatic tumorigenesis. Mol Cancer Ther 2012, 11:24-33

13. Nishii Y, Yamaguchi M, Kimura Y, Hasegawa T, Aburatani H, Uchida H, Hirata K, Sakuma Y: A newly developed anti-Mucin 13 monoclonal antibody targets pancreatic ductal adenocarcinoma cells. Int J Oncol 2015, 46:1781-1787

14. Chauhan SC, Vannatta K, Ebeling MC, Vinayek N, Watanabe A, Pandey KK, Bell MC, Koch MD, Aburatani H, Lio Y, Jaggi M: Expression and functions of transmembrane mucin MUC13 in ovarian cancer. Cancer Res 2009, 69:765-774

15. Wang H, Shen LY, Lin Y, Shi Q, Yang YB, Chen KN: The expression and prognostic significance of Mucin 13 and Mucin 20 in esophageal squamous cell carcinoma. J Cancer Res Ther 2015, 11 Suppl 1: C74-C79

16. Xu ZY, Liu YD, Yang YF, Wang JT, Zhang GD, Liu Z, Fu HC, Wang ZW, Liu HO, Xu JJ: High expression of Mucin13 associates with grimmer postoperative prognosis of patients with non-metastatic clear-cell renal cell carcinoma. Oncotarget 2017, 8:7548-7558

17. Khan S, Ebeling MC, Zaman MS, Sikander M, Yallapu MM, Chauhan N, Yacoubian AM, Behrman SW, Zafar N, Kumar D, Thompson PA, Jaggi M, Chauhan SC: MicroRNA-145 targets MUC13 and suppresses growth and invasion of pancreatic cancer. Oncotarget 2014, 5:7599-7609

18. Khan S, Sikander M, Ebeling MC, Ganju A, Kumari S, Yallapu MM, Hafeez BB, Ise T, Nagata S, Zafar N, Behrman SW, Wan JY, Ghimire HM, Sahay P, Pradhan P, Chauhan SC, Jaggi M: MUC13 interaction with receptor tyrosine kinase HER2 drives pancreatic ductal adenocarcinoma progression. Oncogene 2017, 36: $491-500$

19. Gupta BK, Maher DM, Ebeling MC, Stephenson PD, Puumala SE, Koch MR, Aburatani H, Jaggi M, Chauhan SC: Functions and regu lation of MUC13 mucin in colon cancer cells. J Gastroenterol 2014, 49:1378-1391 
20. He L, Qu L, Wei L, Chen Y, Suo J: Reduction of MIR-132-3p contributes to gastric cancer proliferation by targeting MUC13. Mol Med Rep 2017, 15:3055-3061

21. Chen L, Hu L, Chan TH, Tsao GS, Xie D, Huo KK, Fu L, Ma S, Zheng BJ, Guan XY: Chromodomain helicase/adenosine triphosphatase DNA binding protein 1-like (CHD11) gene suppresses the nucleusto-mitochondria translocation of nur77 to sustain hepatocellular carcinoma cell survival. Hepatology 2009, 50:122-129

22. Chen L, Chan TH, Yuan YF, Hu L, Huang J, Ma S, Wang J, Dong SS, Tang KH, Xie D, Li Y, Guan XY: CHD1L promotes hepatocellular carcinoma progression and metastasis in mice and is associated with these processes in human patients. J Clin Invest 2010, 120:1178-1191

23. Liu L, Dai Y, Chen J, Zeng T, Li Y, Chen L, Zhu YH, Li J, Li Y, Ma S, Xie D, Yuan YF, Guan XY: Maelstrom promotes hepatocellular carcinoma metastasis by inducing epithelial-mesenchymal transition by way of Akt/GSK-3beta/Snail signaling. Hepatology 2014, 59:531-543

24. Yu B, Yang X, Xu Y, Yao G, Shu H, Lin B, Hood L, Wang H, Yang S, Gu J, Fan J, Qin W: Elevated expression of DKK1 is associated with cytoplasmic/nuclear beta-catenin accumulation and poor prognosis in hepatocellular carcinomas. J Hepatol 2009, 50:948-957

25. Huang L, Chen D, Liu D, Yin L, Kharbanda S, Kufe D: MUC1 oncoprotein blocks glycogen synthase kinase 3beta-mediated phosphorylation and degradation of beta-catenin. Cancer Res 2005, 65: 10413-10422

26. Kufe DW: Mucins in cancer: function, prognosis and therapy. Nat Rev Cancer 2009, 9:874-885
27. Packer LM, Williams SJ, Callaghan S, Gotley DC, McGuckin MA: Expression of the cell surface mucin gene family in adenocarcinomas. Int J Oncol 2004, 25:1119-1126

28. MacDonald BT, Tamai K, He X: Wnt/beta-catenin signaling: components, mechanisms, and diseases. Dev Cell 2009, 17:9-26

29. Fang D, Hawke D, Zheng Y, Xia Y, Meisenhelder J, Nika H, Mills GB, Kobayashi R, Hunter T, Lu Z: Phosphorylation of betacatenin by AKT promotes beta-catenin transcriptional activity. J Biol Chem 2007, 282:11221-11229

30. Hino S, Tanji C, Nakayama KI, Kikuchi A: Phosphorylation of betacatenin by cyclic AMP-dependent protein kinase stabilizes betacatenin through inhibition of its ubiquitination. Mol Cell Biol 2005, 25:9063-9072

31. Sheng YH, He YW, Hasnain SZ, Wang R, Tong H, Clarke DT, Lourie R, Oancea L, Wong KY, Lumley JW, Florin TH, Sutton P, Hooper JD, McMillan NA, McGuckin MA: MUC13 protects colorectal cancer cells from death by activating the NF-kappaB pathway and is a potential therapeutic target. Oncogene 2017, 36:700-713

32. Schroeder JA, Adriance MC, Thompson MC, Camenisch TD, Gendler SJ: MUC1 alters beta-catenin-dependent tumor formation and promotes cellular invasion. Oncogene 2003, 22:1324-1332

33. Wen Y, Caffrey TC, Wheelock MJ, Johnson KR, Hollingsworth MA: Nuclear association of the cytoplasmic tail of MUC1 and beta-catenin. J Biol Chem 2003, 278:38029-38039

34. Clevers H: Wnt/beta-catenin signaling in development and disease. Cell 2006, 127:469-480 